\title{
Using a local Web browser as a multimedia platform for lecture and presentation support
}

\author{
MICHAEL E. MILLS \\ Loyola Marymount University, Los Angeles, California
}

\begin{abstract}
As an alternative to commercial multimedia systems, lecturers may wish to consider using a Web browser for multimedia classroom presentations. Many Web browsers, including Netscape and Mosaic, can be configured for use in a "local mode" (i.e., without an active connection to the Internet). In this local mode, files, graphics, audio, and video can be accessed directly from the hard disk of the instructor's computer. By using a laptop computer, an LCD panel, and an overhead projector, an instructor can present a classroom multimedia presentation that can also be published on the Web.
\end{abstract}

Commercial authoring systems have been available for a number of years to help instructors develop and present multimedia classroom presentations. Several articles in this issue explore applications of such systems (e.g., Goolkasian, 1996; Gotsick \& Gotsick, 1996; Rosen \& Petty, 1996; Sekuler, 1996). This paper reviews the advantages and logistics of using an Internet Web browser as a classroom multimedia presentation tool. The browser can be used to replace transparencies, slides, chalkboard, and also to present short video and audio clips, all within an integrated computer-based presentation. In addition, because Web-based presentations are platform independent, they can be viewed from various computer systems, including Mac, PC, UNIX, and so on.

\section{Developing a Multimedia Presentation}

To develop Web-based lecture materials, the instructor will need to convert existing and new lecture materials to hypertext markup language (HTML) formatted files. Slides and/or transparencies that are to be included will need to be scanned and saved as graphics files (e.g., GIF files). Brief sound or video clips that the instructor wishes to include in the presentation will also need to be converted into a compatible digital format (see http://ac.dal.ca/ $\sim$ dong/contents.html for information about various formats and software tools). The entire presentation is then linked together in the master HTML hypertext file.

Users who are familiar with a popular word processor may be able to write HTML files directly with one of several commercial and free HTML editing or conversion utilities. For example, Internet Assistant allows users to use Word for Windows as both a Web browser and as an HTML file editor/converter (see http://www.microsoft. com). In addition, a variety of other HTML authoring tools are available (see http://netlib.org/nhse/reptools/ survey/multimedia.html).

Correspondence should be addressed to M. E. Mills, Psychology Department, Loyola Marymount University, 7900 Loyola Blvd., Los Angeles, CA 90045 (e-mail: mmills@Imumail.lmu.edu).

\section{Using a Web Browser in Local Mode}

Many Web browsers, including Netscape and Mosaic, can be configured for use in what is termed a "local mode" (without the requirement of an active connection to the Internet). In this mode, HTML files, graphics, audio, and video may be accessed directly from the hard disk of the instructor's computer in places where an active internet connection is unavailable.

To use Netscape in local mode (for versions of Netscape prior to 2.0), the file mozock.dll must be downloaded from the Netscape Internet site (http:// www.netscape. com). By installing this file as winsock. dll, the Netscape menu item File/Open File commands can be used to view local HTML files on their hard disk without an Internet connection. Alternately, the File/Location command can be used with many browsers to open files on the hard disk (in Netscape, type the DOS pathname using this format: file:///c: $\backslash \ldots$. pathname... $\backslash$ file.htm).

In addition, it is useful to run the Web browser in full screen mode for lecture support. To accomplish this in Netscape, in the options menu the Show Toolbar, Show Location, and Show Directory Buttons menu options can be toggled on and off, and these options may be saved (Save option). This will allow the presenter to gain back a large chunk of screen real estate for his or her presentation.

To run the Mosaic browser in full screen, Mosaic for Windows has a Presentation Mode. Choose Options/Presentation Mode (or use Alt $+\mathrm{P}$ ) to enter it. Mosaic will go completely full screen, sans title bar, borders, and buttons.

\section{Equipment Setup}

Typical equipment required for a Web-based presentation are a laptop computer, an LCD panel, and an overhead projector and screen. The presentation equipment may be portable so that the instructor is not dependent on resources in the classroom itself (with the exception of the projection screen). The addition of an infrared mouse or trackball will allow the presenter to move freely about the room while still controlling the presentation. In lieu of an LCD panel and overhead projector, a large 
television can be used. If the TV is not VGA compliant, a VGA-to-TV converter will be required.

\section{New Pedagogical Functionality}

A Web-based classroom presentation offers several new areas of instructional functionality to instructors. The top-level hypertext outline can be expanded and collapsed during the lecture by the instructor. This allows the lecturer to present a broad overview of the topics to be covered, to explore specific topics in more depth, and then to return to the next point in the top-level outline before advancing to additional topics. Students will likely be more able to keep in mind the "big structure" and conceptual links being discussed throughout a complicated lecture.

It also offers instructors flexibility in the order and depth of their presentation. If time is running short, topics can easily be skipped without shuffling through transparencies or slides. Conversely, other topics may be explored in greater depth by following links deeper into the hypertext outline. The need for cuing, as well as the setting up of audio and video equipment, is also obviated.

\section{Publishing the Presentation on a Web Server}

Web materials used in lecture can also be made available to students for subsequent review via the "publication" of the presentation on a local network or via the Internet. Or, the instructor may wish to make only a subset of the materials available. In addition, Web-based lecture support materials may be made available to other instructors via publication on the Web. Instructors from around the world can collaborate to develop more informative and powerful multimedia lecture materials. Several examples of such Web-based lecture support presentations are available for viewing and downloading at The World Lecture Hall at http://wwwhost.cc.utexas.edu/ world/lecture. Given these advantages offered by Webbased multimedia presentations, and the opportunities available for world-wide collaboration, Web browsers will likely become the preferred multimedia platform for lecture support.

\section{REFERENCES}

Goolkasian, P. (1996). Getting started with multimedia. Behavior Research Methods, Instruments, \& Computers, 28, 279-281.

Gotsick, J. E., \& Gotsick, P. S. (1996). Multimedia in the classroom. Behavior Research Methods, Instruments, \& Computers, 28, 291 -294.

Rosen, E. F., \& PeTTy, L. C. (1996). Selecting an appropriate multimedia authoring language. Behavior Research Methods, Instruments, \& Computers, 28, 286-290.

SEKULER, R. (1996). Teaching sensory processes with multimedia: One of my teaching assistants is a mouse. Behavior Research Methods, Instruments, \& Computers, 28, 282-285.

(Manuscript received November 13, 1995; revision accepted for publication December 18,1995 .) 